\title{
Analysis of the Components of the Fluid in a Single Plant Cell by High-Performance Capillary Electrophoresis
}

\author{
Susumu Honda $\dagger$, Yasuko Naitoh-Ohta, Kazutaka Togashi and Atsushi Taga \\ Faculty of Pharmaceutical Sciences, Kinki University, Kowakae, Higashi-Osaka 577, Japan
}

\begin{abstract}
The major components of the fluid in a single parenchymatous cell of a citrus fruit were analyzed by various modes of highperformance capillary electrophoresis, including zone electrophoresis in the intact state (direct zone electrophoresis), zone electrophoresis as borate complexes and SDS micellar electrokinetic chromatography, and identified by successive introduction of the cell fluid and a solution containing authentic specimens of the major components, followed by comigration. The validity of identification by this co-migration technique is discussed based on experiments using cinnamyl alcohol and cinnamic acid as model compounds. On the other hand the volume of the cell fluid introduced to a capillary was estimated from the peak width of a neutral component, and the introduced amount of a particular component was determined from its peak area against the calibration curve. From these values of the introduced volume and amount, the concentration of this particular component could be easily estimated. This paper also gives an example of application of this method for determining the ascorbic acid concentration in single parenchymatous cells of various kinds of citrus fruits.
\end{abstract}

Keywords Single cell analysis, citrus fruit parenchymatous cell, capillary electrophoresis

In analyses of biological substances we usually homogenize tissues which contain a huge number of cells, and prepare analytical samples from the homogenates. However, recent progress in biological sciences urges us to obtain information on the chemical components of individual cells; this tendency will grow rapidly in the near future. A number of analytical methods have hitherto been examined for this purpose. Radiolabeling and binding to a specific protein ${ }^{1}$ is a remarkable method. It can easily introduce a radioisotope to a formed complex and allows a specific assay of the component. However, this method has a fatal drawback in that each component requires a corresponding specific protein. In contrast, chromatographic methods, such as micro-scale thin-layer chromatography ${ }^{2}$, gas chromatography coupled with mass spectrometry ${ }^{3}$ and high-performance liquid chromatography (HPLC) ${ }^{4}$, allow simultaneous analysis of the component. However, conventional detection techniques do not afford sensitivities high enough to monitor individual components in single cells. Recently Kennedy and Jorgenson ${ }^{5}$ improved the separation and sensitivity by using HPLC in open tubular capillaries with amperometric detection, and succeeded in the simultaneous identification of neurotransmitters with only two neuron cells of a land snail. They also reported on qunatification based on the conventional internal standard method, involving a series of processes of the homogenization of cells, the

\footnotetext{
† To whom correspondence should be addressed.
}

addition of an internal standard, centrifugation, and an analysis of the components in the supernatant. However, this work was not a literally direct analysis of single cells, and the procedure was rather tardy. The work of Olefirowicz and Ewing ${ }^{6}$ using high-performance capillary electrophoresis (HPCE) should be noted under these circumstances. They directly introduced the cytoplasm of a neuron cell of a pond snail into an extremely narrow capillary and analyzed the components simultaneously with amperometric detection. This can be marked as the memorial example of real single-cell analysis. In their work, the identification of the components (several neurotransmitters) was done by comparing their migration times with those of the authentic specimens with careful control of the electroosmotic flow (EOF). Although they also reported preliminary data on the concentrations of these neurotransmitters, the method seems to have some room for improvement.

HPCE is considered to be an ultimate form of electrophoresis, and has drawn the attention of many scientists owing to its high capabilities. It has been applied to a variety of compounds, including drugs ${ }^{7}$, environmental substances ${ }^{8}$, and biologically important substances, such as amino acids ${ }^{9}$, peptides ${ }^{10}$, proteins $^{11}$, carbohydrates ${ }^{12}$, mono $^{13}$ - as well as oligo ${ }^{14}$-nucleotides. Its primary importance is, needless to say, in its highresolution power. Reproducible quantification by oncapillary detection, as compared to other electrophoretic methods utilizing supporting materials, such as membranes and slab as well as disc gels, is also a great 
advantage of this method. An additional feature that the introduced volume of sample solution is as small as nanoliters or less is also important, as mentioned above in the single cell analysis by the Ewing's group. ${ }^{6}$

Single-cell analysis has hitherto been performed with neurons of land or pond snails, because information on neurotransmitter levels of individual neurons has been considered to be very important from a neurophysiological point of view. These cells have particularly large size among animal cells, and are potentially suitable for pursuing single-cell analysis from a technical viewpoint. Single cell-analysis for plant cells will also be important, although no ample information on its significance has been available. Since every plant cell is surrounded by a rigid cell wall, direct sampling of the cell fluid by inserting one end of a capillary is much easier than in analyzing the components of a flaccid animal cell.

This paper describes a preliminary work on single-cell analysis for plant cells, using parenchymatous cells of citrus fruits as models. It describes the identification of the major components by a special technique of comigration, and discusses the problems underlying such a technique. It also proposes a simple, direct method for estimating the concentrations of components without homogenization and the addition of an internal standard, which is comparable to the method of Olefirowicz and Ewing. ${ }^{6}$

\section{Experimental}

\section{Cells}

Parenchymatous cells of citrus fruits were used. In most of basic studies of peak identification cells of a fruit of Citrus unshuu were used. The volume of the cell fluid in a single cell was $c a .17 \mu \mathrm{l}$ on the average, as roughly estimated from the length of a plug formed when all of the fluid was transferred by capillary action into a $44 \mu \mathrm{m}$ i.d.glass tube for melting-point measurement.

\section{HPCE}

Basic studies of co-migration and concentration determinations were carried out using a Waters Quanta 4000 system (Millipore Corporation, Milford, MA, USA) equipped with a semiautomatic siphonic sampler, a thermostated bath and a UV detector with changeable interference filters. An analytical capillary $(50 \mu \mathrm{m}$ i.d., $375 \mu \mathrm{m}$ o.d., $60 \mathrm{~cm}$ ) was obtained from Polymicro Technologies (Phoenix, AZ, USA). Adetection window ( $c a$. $500 \mu \mathrm{m}$ length) was made at a $30-\mathrm{cm}$ position from the inlet. After a solution containing an equimolar amount ( $1 \mathrm{mM}$ ) of cinnamyl alcohol (neutral marker) and cinnamic acid (reference) in $50 \mathrm{mM}$ phosphate buffer (pH 6.8) was introduced for various sampling times, a potential of $20 \mathrm{kV}$ was constantly applied until both components migrated to the detection window. Analysis of cell fluid components were performed using a JASCO CE-800 system, because it allowed easier operation of cell fluid introduction since the capillary inlet was freely movable. It comprised an 890-CE highvoltage supply, an $875-\mathrm{CE}$ continuous wave-type UV detector, a pair of polytetrafluoroethylene (PTFE) reservoirs, and a sampling device for manual operation based on gravity. A capillary of the same i.d. and o.d. was obtained from Scientific Glass Engineering (Melbourne, Australia), but its length was $45 \mathrm{~cm}$. The carrier solutions used in direct zone electrophoresis, zone electrophoresis as borate complexes, and sodium dodecyl sulfate (SDS)-mediated micellar electrokinetic chromatography modes were $100 \mathrm{mM}$ phosphate buffer (pH 6.8), $200 \mathrm{mM}$ borate buffer (pH 10.5), and $100 \mathrm{mM}$ phosphate buffer (pH 6.8) containing SDS to a concentration of $50 \mathrm{mM}$, respectively.

\section{Sample introduction}

In basic studies of the co-migration and concentration determination, sample solutions were introduced while keeping the sample solution level at $10 \mathrm{~cm}$ higher than the cathodic solution level. In single-cell analysis a 5-mm portion of the polyimide coating was removed at the anodic end by burning, and the end was carefully sharpened to give an outer diameter of $c a .100 \mu \mathrm{m}$ by using sandpaper. The pointed end was directly stabbed into a parenchymatous cell of a citrus fruit, and the anodic end was raised together with the stabbed cell $8 \mathrm{~cm}$ higher than the cathodic solution level for $10 \mathrm{~s}$. The cell fluid was allowed to be introduced spontaneously to the capillary by the combined effects of the hydrodynamic pressure and the inner pressure of the cell.

\section{Results and Discussion}

Reliability of the successive introduction technique of comigration for identification

In identifying the peaks, a simple comparison of the migration times between a component of a sample and an authentic specimen is not necessarily expedient, since the migration time may vary considerably during a series of analyses. Especially, when the rinse of the capillary is incomplete, the velocity of EOF may vary over a wide range, resulting in a fluctuation of the migration time. In order to avoid an incorrect identification due to EOF fluctuation, co-migration, which is similar to co-elution in chromatography, is a useful method. Usually, in both co-migration and co-elution sample and authentic specimen solutions are mixed in a vial, and an aliquot is analyzed. The other part of the mixed solution is usually discarded, because the sample is difficultly recovered from it. A much more convenient technique is to successively introduce a sample solution and an authentic specimen solution, or vise versa. Both solutions are efficiently mixed in a capillary or a column during migration, and the combined zones give rise to a single peak. Identification by this technique has a great advantage in that it can be performed using quite minute amounts of the sample and authentic specimen. Only a nanoliter or smaller portions of their solutions are 


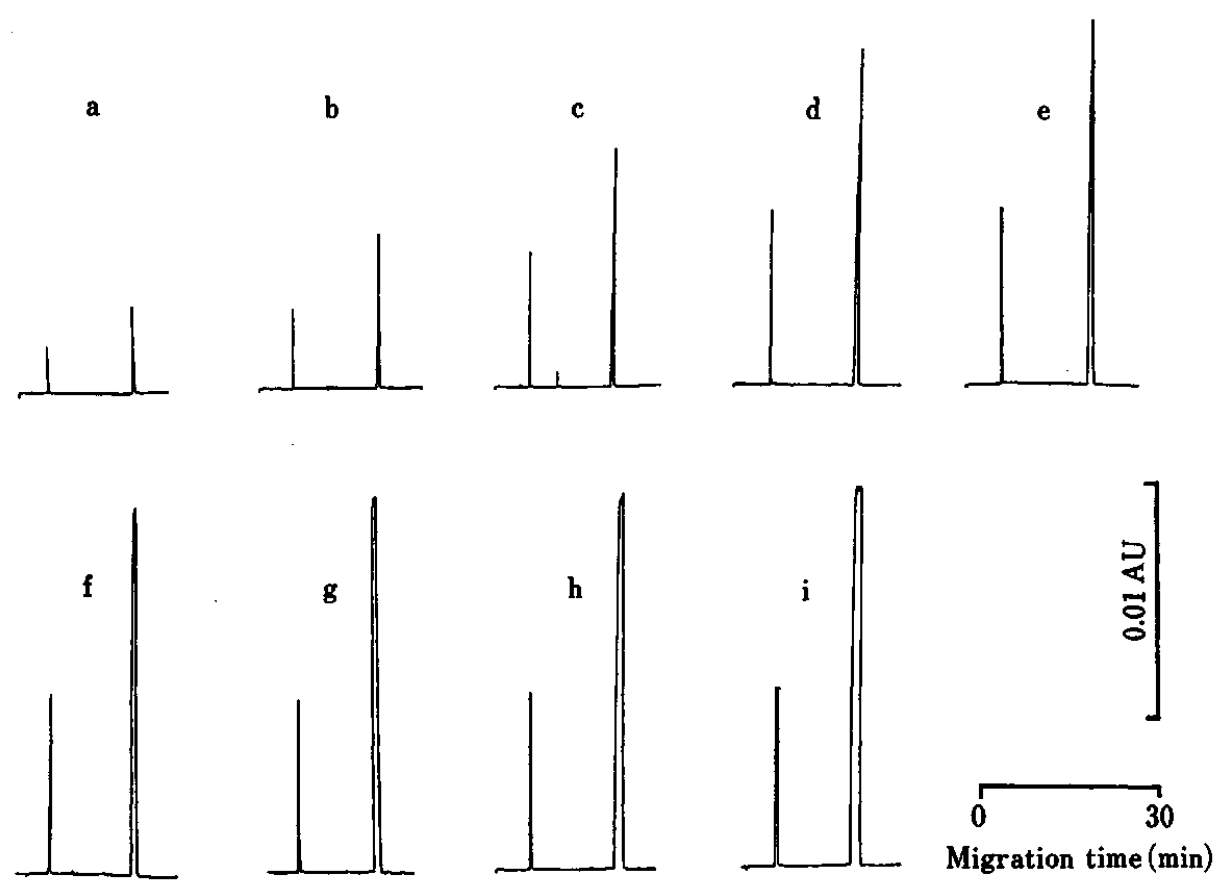

Fig. 1 Effect of the sampling time on the shapes of the cinnamyl alcohol peak (front peak) and cinnamic acid peak (rear peak) in the successive-introduction technique of co-migration. A solution containing cinnamyl alcohol and cinnamic acid, both in a $1.0 \mathrm{mM}$ concentration, in $50 \mathrm{mM}$ phosphate buffer ( $\mathrm{pH} \mathrm{6.8)}$, was introduced twice in series for various sampling times, and analyzed immediately. The first introduction can be assumed to be the introduction of either the sample solution or the authentic specimen solution, and the second introduction to be vise versa. Capillary, fused silica (Polymicro Technologies, $50 \mu \mathrm{m}$ i.d., $375 \mu \mathrm{m}$ o.d., $60 \mathrm{~cm}$ ); applied voltage, $20 \mathrm{kV}$; detection, $\mathrm{UV}$ absorption at $230 \mathrm{~nm}$; sampling method, hydrodynamic $(8 \mathrm{~cm})$. Sampling time: $2 \mathrm{~s}$ each (a), $5 \mathrm{~s}$ each (b), $10 \mathrm{~s}$ each (c), $20 \mathrm{~s}$ each (d), $30 \mathrm{~s}$ each (e), $40 \mathrm{~s}$ each (f), $50 \mathrm{~s}$ each (g), $60 \mathrm{~s}$ each (h), $90 \mathrm{~s}$ each (i).

analyzed, and the other portions are left unused. However, there seem to be a number of problems to be considered in order to achieve a reliable identification of the analytes by this successive introduction technique.

We performed a model experiment to examine the effect of the sampling time, and accordingly introduced volume, on the peak broadening, using a solution containing cinnamyl alcohol and cinnamic acid in an equimolar concentration at the same buffer as the carrier. This solution was introduced twice successively to a capillary for various sampling times. However, the sampling times of the first and second introductions were kept equal in all analyses. We can assume that the first introduction was for the sample solution and the second introduction was for the authentic specimen solution, or vise versa. Though these compounds have absorption maxima at different wavelengths, both were monitored at a common wavelength of $230 \mathrm{~nm}$ after having migrated at a constant applied voltage of $20 \mathrm{kV}$. Figure 1 shows how the peak shape changed with the sampling time by these successive (double) introductions. No twinheaded peaks appeared in all of the electropherograms, indicative of almost the complete mixing of two zones. Since this experiment was performed by using a neutral phosphate buffer as a carrier, cinnamyl alcohol had no electric charge, whereas cinnamic acid was dissociated to give an anion. Therefore, cinnamyl alcohol (front peak in each electropherogram; migration time, $5 \mathrm{~min}$ ) migrated only by EOF, whereas cinnamic acid (rear peak in each electropherogram; migration time, $20 \mathrm{~min}$ ) migrated slower due to the combined effects of EOF and electrophoretic migration. We can note that although the peak height of cinnamyl alcohol initially increased with the sampling time, it reached a plateau at sampling times of $20 \mathrm{~s}$ each (Fig. 1d). The change in the peak height of cinnamic acid was similar, but reached a plateau at a longer sampling time of $30 \mathrm{~s}$ each (Fig. 1e). After the plateaux were reached, the peaks of both compounds became flat. The cinnamic acid peak became almost trapezia by sampling for $90 \mathrm{~s}$ each.

Table 1 gives the change in the number of theoretical plates $(N)$ for these peaks along with the sampling time. It also gives the $N$ values for the single introduction of two-fold volumes of the solution, as a reference (figure not shown). The $N$ values for both single (two-fold volume) and double introductions naturally decreased, as the sampling time increased. The $N$ value of the cinnamyl alcohol peak by double introductions was 
Table 1 The numbers of theoretical plates of cinnamyl alcohol and cinnamic acid peaks for various sampling times

\begin{tabular}{|c|c|c|c|c|}
\hline \multirow{3}{*}{$\begin{array}{c}\text { Sampling } \\
\text { time/s }\end{array}$} & \multicolumn{4}{|c|}{ Number of theoretical plates $\left(\times 10^{-3}\right)$} \\
\hline & \multicolumn{2}{|c|}{ Double introductions } & \multicolumn{2}{|c|}{ Single introduction } \\
\hline & $\begin{array}{c}\text { Cinnamyl } \\
\text { alcohol }\end{array}$ & $\begin{array}{l}\text { Cinnamic } \\
\text { acid }\end{array}$ & $\begin{array}{c}\text { Cinnamyl } \\
\text { alcohol }\end{array}$ & $\begin{array}{l}\text { Cinnamic } \\
\text { acid }\end{array}$ \\
\hline $\begin{array}{l}2, \text { each } \\
4\end{array}$ & $89(0.86)$ & $77(1.00)$ & 103 & 77 \\
\hline $\begin{array}{l}5 \text {, each } \\
10\end{array}$ & $58(0.89)$ & $49(1.02)$ & 65 & 48 \\
\hline $\begin{array}{l}10, \text { each } \\
20\end{array}$ & $44(0.92)$ & $31(1.00)$ & 48 & 31 \\
\hline $\begin{array}{l}20 \text {, each } \\
40\end{array}$ & $17(0.94)$ & $17(1.00)$ & 18 & 17 \\
\hline $\begin{array}{l}30 \text {, each } \\
60\end{array}$ & $8.0(1.00)$ & $7.9(1.01)$ & 8.0 & 7.8 \\
\hline $\begin{array}{l}40, \text { each } \\
80\end{array}$ & $3.8(1.03)$ & $3.6(1.00)$ & 3.7 & 3.6 \\
\hline $\begin{array}{l}50 \text {, each } \\
100\end{array}$ & $2.4(1.00)$ & $2.3(0.96)$ & 2.4 & 2.4 \\
\hline $\begin{array}{l}60, \text { each } \\
120\end{array}$ & $2.0(1.05)$ & $1.9(1.00)$ & 1.9 & 1.9 \\
\hline $\begin{array}{l}90, \text { each } \\
180\end{array}$ & $0.79(1.00)$ & $0.79(1.03)$ & 0.79 & 0.77 \\
\hline
\end{tabular}

The numbers in parentheses are the proportions to single introduction.

smaller than that by the corresponding single introduction until $10 \mathrm{~s}$ each, but they became almost equal after $30 \mathrm{~s}$ each. In other words, the $N$ ratio of the double to single introductions increased, as sampling time became longer to reach unity at $30 \mathrm{~s}$ each. The deviation from unity in short sampling times was presumably due to the relatively large contribution of turbulence at the boundary of the two zones. The influence of boundary turbulence on the column efficiency would be greater in the faster moving component (cinnamyl alcohol) and for a shorter sampling time, because the mixed zone at the detector is narrower and the migration (accordingly mixing) time is shorter. However, the effect of boundary turbulence became negligible for sampling times of more than $30 \mathrm{~s}$ each. The $N$ values of the cinnamic acid peak by both introduction modes were almost identical, regardless of the sampling time, presumably due to the ample time for mixing. These observations indicate that there is practically no difference in the $N$ values between single introduction and double introductions, provided that samples and the authentic specimen solutions are introduced in adequate sampling times (larger than $30 \mathrm{~s}$ each). Double introductions for too short sampling times caused a moderate decrease of column efficiency, as compared to single introduction, and too long sampling times gave flattened peaks. As a matter of course, identification based on co-migration by this double (successive) introduction technique under such conditions would be unreliable. Under the conditions employed, the appropriate range of sampling time was considered to be $10-20 \mathrm{~s}$ each for cinnamyl alcohol (the faster moving component) and 10-30s each for cinnamic acid (the slower moving component). The present argument is based on an experiment, in which both the presumed sample and presumed authentic specimen solutions were introduced for equal sampling times. If the sample solution is introduced for shorter sampling time than the authentic specimen solution, boundary turbulence would have a smaller influence on the zone broadening. However, the successive introduction of these two solutions in different sampling times would give rise to another problem concerning peak symmetry. It is evident that the appearance of an asymmetric peak is unfavorable for peak identification, because it makes judging the identity of a sample with the authentic specimen difficult. Therefore, the use of such conditions should be avoided.

In the above discussion the authentic specimen solution contained only one kind of authentic specimen. However, the use of a solution containing multiple authentic specimens allows the simultaneous identification of the corresponding components. Such work is presented in the following section for single-cell analysis.

Identification based on co-migration by this successive-introduction technique should be performed using a solution containing the authentic specimen at a concentration as close as possible to that of the sample solution. Although the same medium was used for the assumed sample and the assumed authentic specimen solutions in the present model experiment, such an accordance of media is practically difficult in the component analysis of biological samples, because the sample solution is generally in a complex matrix. Even though this disaccord is inevitable, at least the authentic specimen solution should be prepared by dissolving it in the same buffer as that of the carrier.

\section{Analysis of the components of a single cell by various separation modes}

Parenchymatous cells of citrus fruits continue to swell during its growing process and come to store juicy fluid inside. The following analyses were performed using such fluids in single parenchymatous cells of a fruit of Citrus unshuu.

Co-migration was performed by successive introduction of the cell fluid, followed by a solution containing authentic specimens of the major components (naringin, hesperidin, $\alpha$-tocopherol and ascorbic acid), together with mesityl oxide as a neutral marker, in the same buffer as carrier. On the basis of the foregoing discussion the sampling time was $10 \mathrm{~s}$ each in all of the analyses, and the concentrations of these authentic specimens were adjusted so as to give approximately the same responses as those of the components of the cell fluid, based on the preliminary results obtained by this procedure using other cells from the same fruit.

Analyses of the authentic specimens solution alone by direct zone electrophoresis in the neutral carrier indicated that naringin, hesperidin and $\alpha$-tochopherol were 


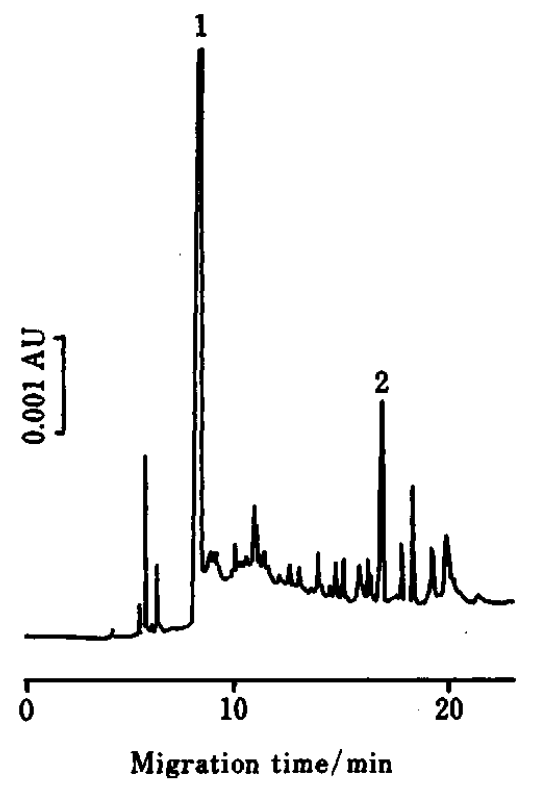

Fig. 2 Identification of the major components of the fluid of a single parenchymatous cell of a Citrus unshu fruit by the successive-introduction technique of co-migration. The cell fluid was introduced to a capillary, followed by an authentic specimen solution containing mesityl oxide as an internal standard; consecutive plugs were analyzed immediately by direct zone electrophoresis. Capillary, fused silica (Scientific Glass Engineering, $50 \mu \mathrm{m}$ i.d., $375 \mu \mathrm{m}$ o.d., $45 \mathrm{~cm}$ ); carrier, $50 \mathrm{mM}$ phosphate buffer (pH 6.8); applied voltage, $15 \mathrm{kV}$; detection, $\mathrm{UV}$ absorption at $220 \mathrm{~nm}$; sampling method, hydrodynamic $(8 \mathrm{~cm}, 8 \mathrm{~s})$. Peaks were assigned by the successive-introduction technique of comigration with multiple authentic specimens. 1=naringin, hesperidin, $\alpha$-tocopherol, $2=$ =ascorbic acid.

not separated from each other, giving a rapidly moving single peak; however, co-migration with a cell fluid increased the intensity of this peak (Fig. 2). Although three compounds have the phenolic hydroxyl group(s), ionization to the phenolate ion was not favored under such neutral conditions. The rapid appearance of this peak is evidence of poor ionization. The peak at $c a$. 17 min could be assigned to ascorbic acid due to its enhancement by co-migration with the authentic specimens solution. Since the greater part of the carboxyl group in this organic acid was ionized even under these neutral conditions, its mobility was high and it moved slowly.

Figure 3 shows the result of the co-migration observed for another parenchymatous cell by zone electrophoresis in an alkaline borate buffer. It is well known that polyhydroxyl compounds, such as carbohydrates, form anionic borate complexes in situ in a solution containing a borate salt. ${ }^{12}$ The resultant complexes are separated by zone electrophoresis like ordinary anions. The electrophoretic mobility is dependent on the ease of complexation. The conditions employed in Fig. 3 are those typically used for the analysis of monosac-

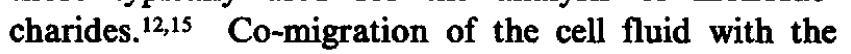

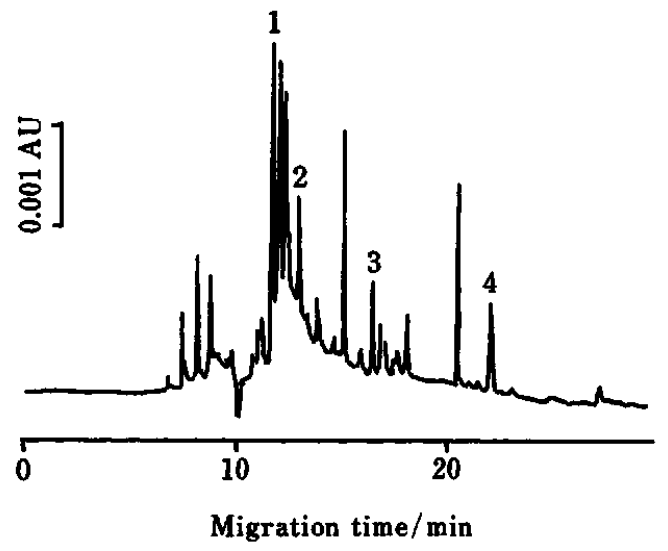

Fig. 3 Identification of the major components of the fluid of a single parenchymatous cell of a Citrus unshu fruit by the successive-introduction technique of co-migration. The introduction of the cell fluid and an authentic specimens solution was in the same manner as in Fig. 2, though the analysis was based mainly on zone electrophoresis as borate complexes. Carrier, $100 \mathrm{mM}$ borate buffer (pH 10.5). The other conditions as in Fig. 2. Peaks: 1=hesperidin, $2=$ naringin, $3=\alpha$-tocopherol, $4=$ ascorbic acid.

authentic specimens solution permitted the identification of peaks at $11.7 \mathrm{~min}, 13.0 \mathrm{~min}$ and $16.6 \mathrm{~min}$ as hesperidin, naringin, and $\alpha$-tocopherol, respectively. The use of the borate buffer as carrier allowed the separation of the flavonoid glycosides (hesperidin and naringin) due to the difference in the ease of complexation of the hydroxyl groups in their carbohydrate moieties. $\alpha$-Tocopherol migrated the slowest among these compounds, presumably because its phenolic hydroxyl group was the most easily ionized by the alkalinity of the carrier used. Ascorbic acid migrated much slower than these compounds, giving its peak at $c a$. $22 \mathrm{~min}$. Figure 3 shows other peaks that were not negligible, but could not be identified at this stage:

Figure 4 shows an example of co-migration by SDSmediated micellar electrokinetic chromatography. Separation is based on the difference in the magnitude of solubilization to the moving SDS micelles in this mode, and the magnitude of solubilization increased with increasing concentrations of SDS in carrier, as expected from the original work of Terabe et al. ${ }^{16}$ The $\mathrm{pH}$ of carrier is also a decisive factor for solubilization. The use of alkaline carriers was disadvantageous for solubilization (electropherograms not shown), because the phenolic hydroxyl groups in the flavonoid glycosides and $\alpha$-tocopherol were ionized to a considerable extent to reduce hydrophobicity. Under neutral conditions ionization of the phenolic hydroxyl group was moderately suppressed, and solubilization was favored to some extent. Acidic carriers were much more favorable for the suppression of ionization of the phenolic hydroxyl groups, though the migration time increased due to reduced velocity of EOF (electropherograms not shown). 


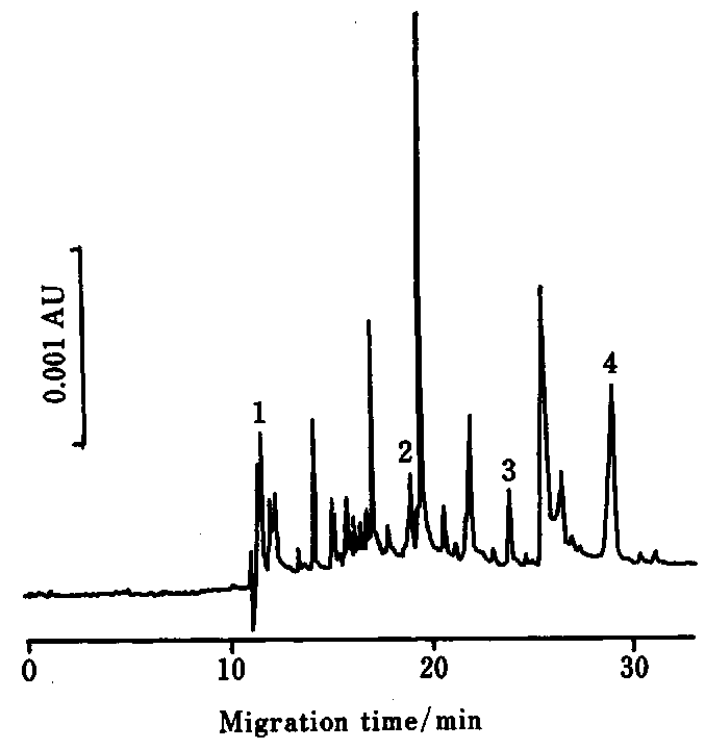

Fig. 4 Identification of the major components of the fluid of a single parenchymatous cell of a Citrus unshu fruit by the successive-introduction technique of co-migration. The introduction of the cell fluid and an authentic specimen solution was in the same manner as in Fig. 2, but analysis was based on SDS-micellar electrokinetic chromatography. Carrier, $50 \mathrm{mM}$ phosphate buffer (pH 6.8) containing SDS to a concentration of $50 \mathrm{mM}$. The other conditions as in Fig. 2. Peaks: $1=$ naringin, $2=\alpha$-tocopherol, $3=$ hesperidin, $4=$ ascorbic acid.

Figure 4 is an electropherogram of co-migration obtained at $50 \mathrm{mM}$ SDS (pH 6.8), the standard conditions of micellar electrokinetic chromatography of carbohydrate derivatives. ${ }^{12}$ Co-migration with the authentic specimens realized the identification of naringin, $\alpha$ tocopherol, and hesperidin.: They were well separated in this order. Ascorbic acid migrated slower by zone electrophoresis due to ionization of the carboxyl group. In addition to these peaks a number of well-separated intense peaks were observed (Fig. 4), though their identification was left for future studies.

In these experiments of co-migration, the ionic strength and $\mathrm{pH}$ of the cell fluid was not identical with those of the authentic specimens solution as well as carrier solutions. However, such a mismatch did not cause any practical inconvenience in the identification by this successive-introduction technique of co-migration, at least under the conditions employed.

\section{Estimation of introduced volume from peak width}

In HPCE, simultaneous determination of the components of a sample is generally performed by the internal-standard (IS) method, in a similar manner as in HPLC. In this method a specified amount of IS is added to a sample solution of a known volume, and each component is determined by using a calibration curve, prepared by plotting the relative peak area to IS vs. relative amount to IS using the authentic specimen solutions. However, this IS method is hardly applicable to a component analysis of the fluid in a single cell, because its exact volume is unknown. The approximate volume might be estimated by transferring the cell fluid to an appropriate vessel, such as a glass capillary of known i.d., and measuring the plug length of the transferred fluid. However, this method is not accurate, because complete transference cannot be expected. In addition, the volume reduction by evaporation during operation is not negligible.

Olefirowicz and Ewing ${ }^{6}$ adopted a method based on the velocity of EOF. However, they introduced sample solutions by electromigration. This method has a shortcoming in that the concentrations of the analytes in the solution introduced to the capillary are not necessarily identical with those in the cell fluid. They estimated the introduced volume, assuming that the velocity of introduction of the cell fluid is proportional to that of EOF in analysis. In reality, however, the cell fluid is in a different medium from the carrier solution. Therefore, their method might pose a problem for estimating the introduced volume. Based on this consideration we employed a different method involving the relationship between the length of the sample plug and the peak width.

In this method a target compound should be selected, which moves at the same velocity as that of the introduced cell fluid. In an analysis by zone electrophoresis, in either a neutral or alkaline carrier, an inherent neutral compound in the cell fluid is the most desirable target. If a neutral component is absent in the cell fluid, a neutral marker should be added together with the authentic specimens as a substitute. In the micellar electrokinetic chromatography mode the most suitable target is methanol, because it moves with water and is not incorporated into the micelles at all.

When a solution containing a neutral compound is introduced to a capillary by pressure and a potential is applied between both ends, it is migrated through the capillary by EOF to reach the detector window. The introduced solution initially forms a cylindrical plug, but changes to a spindle due to molecular diffusion. If there were no effect of molecular diffusion, the cylindrical plug would reach the detector window without changing its shape, and the signal would form a rectangle. In reality, however, the signal forms a peak having a Gaussian distribution in normal cases. If we let the height and width of the imaginative rectangle be $H_{\max }$ and $D$, respectively, and the height and width at the half height of the actually observed peak be $H$ and $W_{1 / 2}$, respectively, the following approximate relation will be obtained;

$$
H_{\max } \times D=H \times W_{1 / 2},
$$

$D$ can be correlated to the plug length $(\delta)$ as follows:

$$
D=\frac{a \times t_{0} \times \delta}{l},
$$

where $a, t_{0}$ and $l$ are the chart speed, the migration time of 

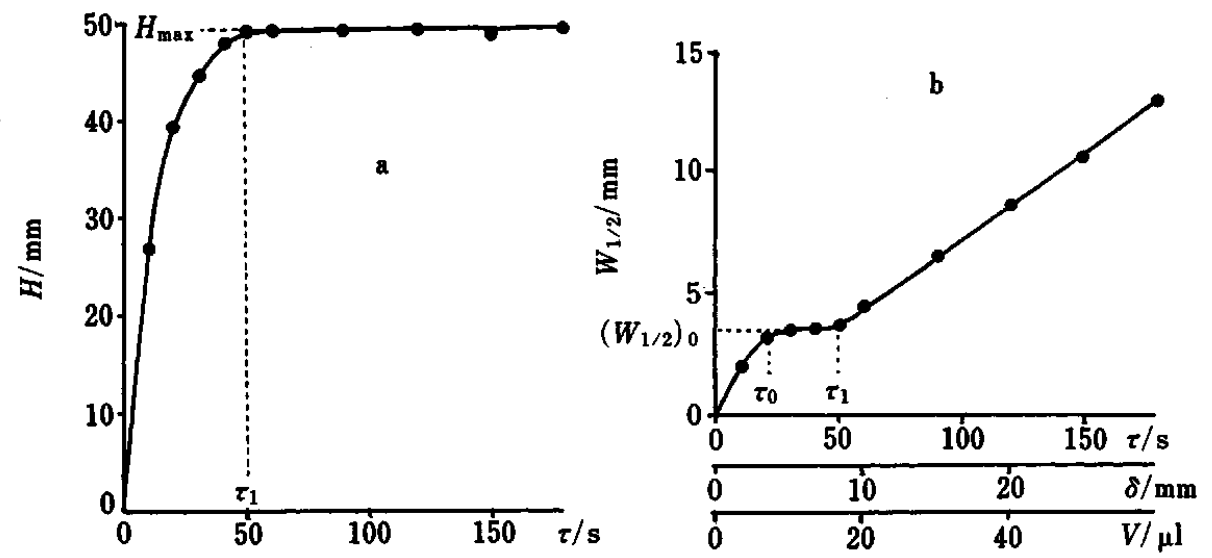

Fig. 5 Change of the height $(H, a)$ and the width at half height $\left(W_{1 / 2}, b\right)$ of the cinnamyl alcohol peak with sampling time $(\tau)$, accordingly the plug length of the sample solution $(\delta)$, and its introduced volume $(V)$. Capillary, fused silica (Polymicro Technologies, $50 \mu \mathrm{m}$ i.d., $375 \mu \mathrm{m}$ o.d., $60 \mathrm{~cm}$ ); concentration of cinnamyl alcohol, $1.0 \mathrm{mM}$; chart speed, $0.5 \mathrm{~mm} / \mathrm{s}$. The other conditions as in Fig. 2.

a neutral marker and the capillary length between the inlet and detection window, respectively. In fact, the detection is not done at one point, but is performed over a narrow width of the slit, although this slit-width problem is usually negligible. Therefore, the following equation is derived:

$$
\delta=\frac{l}{a \times t_{0}} \times D=\frac{l}{a \times t_{0}} \times \frac{H}{H_{\max }} \times W_{1 / 2} .
$$

In Eq. (3), $a, t_{0}$ and $t$ are constant, when the neutral marker is analyzed in the same capillary at the same applied voltage, while $H, H_{\max }$ and $W_{1 / 2}$ are varied depending on its concentration $(C)$ and sampling time $(\tau)$.

In order to correlate these variable factors, the change in the peak shape with $\tau$ was investigated. As shown in Fig. 5a, obtained for a cinnamyl alcohol solution in $50 \mathrm{mM}$ phosphate buffer (pH 6.8), although $H$ increased almost linearly with $\tau$ at first, the increasing rate was reduced to reach a plateau at $\tau=\tau_{1}(c a .50 \mathrm{~s})$. Since a neutral marker having a specified concentration gives a correspondingly fixed value of $\boldsymbol{H}_{\max }(c a .50 \mathrm{~mm})$, the $H / H_{\max }$ ratio should give a change similar to that of $H$. It is noticed that $W_{1 / 2}$ rapidly increased at first to reach a plateau of $\left(W_{1 / 2}\right)_{0}$ at $\tau_{0}(\mathrm{ca} .20 \mathrm{~s})$, and remained unchanged until $H$ or the $H / H_{\max }$ ratio reached the onset of the plateau at $\tau_{1}(c a .50 \mathrm{~s}$, Fig. $5 \mathrm{~b})$. Although the value of $H$ and $H_{\max }$ changed with the concentration of the neutral marker, $W_{1 / 2}$ remained almost unchanged, as can be seen from the data in Table 2. After $H$ reached a plateau at $\tau_{1}$, it remained constant, whereas $W_{1 / 2}$ continuously increased in the 1st-order function of $\tau$. Since the plug length $(\delta)$ is proportional to $\tau$ in the hydrodynamic sample introduction, $\delta$ can be expressed as $k \times \tau$, where $k$ is a constant. The abscissa of Fig. $5 \mathrm{~b}$ is also expressed by $\delta$. The $k$ value under the conditions employed was $0.167 \mathrm{~mm} / \mathrm{s}$ on the average, when the plug
Table 2 Effect of cinnamyl alcohol concentration on peak width at half height $\left(W_{1 / 2}\right) \quad \tau=30 \mathrm{~s}$

\begin{tabular}{lcccccc}
$C / \mathrm{mM}$ & $4 \times 10^{-4}$ & $6 \times 10^{-4}$ & $8 \times 10^{-4}$ & $1 \times 10^{-3}$ & $2 \times 10^{-3}$ & $5 \times 10^{-3}$ \\
$W_{1 / 2} / \mathrm{mm}$ & 2.8 & 2.8 & 2.8 & 2.9 & 2.9 & 2.9 \\
\hline$\tau=30 \mathrm{~s}$. & & & & & &
\end{tabular}

length of a $0.05 \mathrm{w} / \mathrm{w} \%$ Methylene Blue solution in $1 \mathrm{M}$ sodium hydroxide as a reference was measured at various sampling times by using a micrometer scale.

The foregoing discussion suggests that $\delta$ can be estimated by measuring $W_{1 / 2}$, if the $W_{1 / 2}-\tau$ curve is prepared for the system to be used. However, the use of this relationship for estimating $\delta$ has a limitation; a number of possible $\delta$ values exist for $\left(W_{1 / 2}\right)_{0}$. In a $W_{1 / 2}$ region lower than the $\left(W_{1 / 2}\right)_{0}$ an estimation of $\delta$ is not reliable. Although every $W_{1 / 2}$ value higher than $\left(W_{1 / 2}\right)_{0}$ can be used theoretically, the peak of the neutral marker will become flat at too high $W_{1 / 2}$ values. Under such conditions the analytes are not in an ideal state of separation. Nevertheless, the selection of $W_{1 / 2}$ values higher than $\left(W_{1 / 2}\right)_{0}$, but not very far from it, permits an estimation of the plug length without any remarkable inconvenience. The volume $(V)$ of the solution introduced to the capillary can be calculated as $\delta \times \pi \times r^{2}$, where $r$ is the inner radius of the capillary. The abscissa of Fig. $5 b$ is also plotted by the thus-calculated $V$. The reliability of the proposed method depends on the accuracy of the $W_{1 / 2}$ measurement. It is absolutely necessary to record the peak of the neutral marker at the highest chart speed. The allowable significant figures are of two digits in practical analyses by this method.

\section{Estimation of the introduced amount of a component}

The introduced amount of any particular component of a sample can be easily estimated using the calibration 
Table 3 Ascorbic acid concentrations of single parenchymatous cells of various citrus fruits

\begin{tabular}{lrccc}
\hline Species & $\begin{array}{c}\text { Zone } \\
\text { width/ } \\
\text { mm }\end{array}$ & $\begin{array}{c}\text { Introduced } \\
\text { volume/ } \\
\mathrm{nl}\end{array}$ & $\begin{array}{c}\text { Introduced } \\
\text { amount/ } \\
\text { pmol }\end{array}$ & $\begin{array}{c}\text { Ascorbic acid } \\
\text { concentration/ } \\
\text { mM }\end{array}$ \\
\hline C. unshuu & 11.0 & 21.7 & 58.6 & 2.7 \\
C. sinensis & 2.6 & 24.5 & 149 & 6.1 \\
C. limon & 14.1 & 27.6 & 99.4 & 3.6 \\
C. paradisi & 12.5 & 24.5 & 100 & 4.1 \\
C. hassaku & 11.1 & 21.8 & 172 & 7.9 \\
\hline
\end{tabular}

curve (relationship between the peak area and the absolute introduced amount of the component) prepared from standard solutions of known concentrations of an authentic specimen. The absolute introduced amount of a standard solution $\left(A_{\mathrm{s}}\right)$ can be calculated as $C_{\mathrm{s}} \times V_{\mathrm{s}}$, where $C_{\mathrm{s}}$ and $V_{\mathrm{s}}$ are its concentration and the introduced volume, respectively. The values of $C_{s}$ are known, and the values of $V_{\mathrm{s}}$ can be obtained as $\pi \times \delta \times r^{2}$, accordingly $k \times \pi \times \tau \times r^{2}$, in a similar manner as mentioned above for a single-cell analysis. Subscript $s$ is also referred to the standard solution. For example, the calibration curve of ascorbic acid obtained for the zone electrophoresis mode under the conditions given in Fig. 2 was shown to be linear $\left(A_{\mathrm{s}}=3.3 \times 10^{5} C_{\mathrm{s}}-0.06, R=0.996\right.$ for $r=0.25 \mathrm{~mm}$ and $\tau=10 \mathrm{~s} ; A_{\mathrm{s}}$ in pmol, $C_{\mathrm{s}}$ in $\mathrm{M}$ ) at least in a range of $2-$ 200 pmol, when measured by UV absorption at $200 \mathrm{~nm}$. The absolute introduced amount of the authentic specimen could also be determined by a flow-injection analysis. The separated component zone was driven out from the capillary by hydrodynamic pressure, and determined by flow-injection analysis. The thusobtained calibration curve of ascorbic acid was almost the same as that obtained by the $C_{\mathrm{s}} \times V_{\mathrm{s}}$ method mentioned above (figure not shown).

\section{Estimation of the ascorbic acid concentrations in single cells of various citrus fruits}

As mentioned above, a simple method was established to estimate the volume of the introduced sample solution from the peak width of a neutral component, and the absolute introduced amount of any particular component using the calibration curve. Table 3 shows some data of the ascorbic acid concentration obtained for single parenchymatous cells of various kinds of citrus fruits. The thus-obtained ascorbic acid concentration showed a variation over a range of $2.7-7.9 \times 10^{-3} \mathrm{M}$. Single cells of Citrus sinensis and Citrus hassaku gave rather high concentrations. These data are only preliminary, but should be evaluated as the first example of an estimation of ascorbic acid concentrations in single cells. A discussion on the significance of the obtained data in relation to histochemical phenomena is too hasty at this stage.

In the present work we first focused on the validity of the successive introduction technique for multiple comigration, aiming at a simultaneous identification of the components of a solution having a limited unknown volume, such as the cell fluid, and gave typical examples of a valid identification by this technique. In parallel with identification, we examined the possibility of estimating the concentration of a particular component from the peak width. Unlike the electromigration-EOF method $^{6}$, the proposed method ensures that the concentration of the component in the solution introduced to a capillary is completely equal to that in the cell fluid, because it is based on sampling by hydrodynamic pressure. The pressure- and vacuum-sampling methods will have the same advantage. Although the proposed method is not perfectly ideal, it will allow a rapid estimation of the constituents of living single cells by the simplest procedure. The parenchymatous cells employed as models had a rather large size. A special sampling technique and the use of a narrower capillary will be required for smaller cells. For the components not absorbing UV light a special technique, such as derivatization at the inlet of a capillary ${ }^{17}$ prior to analysis, may be useful. Studies on such problems are now going on.

\section{References}

1. R. M. McCaman, D. Weinrich and H. Borys, J. Neurochem., 21, 473 (1973).

2. N. N. Osborne, Nature [London], 270, 622 (1977).

3. D. J. McAdoo, in "Biochemistry of Characterized Neurons" ed N. N. Osborne, p. 19, Pergamon Press, New York, 1978.

4. L. C. Ment, R. L. Meuller and D. A. Haycock, J. Neurochem., 41, 481 (1983).

5. R. T. Kennedy and J. W. Jorgenson, Anal. Chem., 61, 436 (1989).

6. T. M. Olefirowicz and A. G. Ewing, Anal. Chem., 62, 1872 (1990).

7. e.g. S. Fujiwara and S. Honda, Anal. Chem., 58, 1811 (1986).

8. e.g. K. Otsuka, S. Terabe and T. Ando, J. Chromatogr., 348, 39 (1985).

9. e.g. J. W. Jorgenson and K. D. Lukacs, Anal. Chem., 5, 298 (1981).

10. e.g. P. D. Grossman, J. C. Colburn and H. H. Lauer, Anal. Biochem., 179, 28 (1989).

11. e.g. H. H. Lauer and D. McManigill, Anal. Chem., 58, 166 (1986).

12. e.g. S. Honda, S. Iwase, A. Makino and S. Fujiwara, Anal. Biochem., 176, 72 (1989).

13. e.g. D. Burton, M. Sepaniak and M. Maskarinec, Chromatographia, 21, 583 (1986).

14. e.g. A. S. Cohen, S. Terabe, J. A. Smith and B. L. Karger Anal. Chem., 59, 1021 (1987).

15. S. Honda, S. Suzuki, A. Nose and K. Yamamoto, Carbohydr. Res., 215, 193 (1991).

16. S. Terabe, K. Otsuka and T. Ando, Anal. Chem., 57, 834 (1985).

17. A. Taga and S. Honda, J. Chromatogr., 742, 243 (1996).

(Received March 7, 1997)

(Accepted April 18, 1997) 